DOI: $10.17805 /$ zpu.2016.2.6

\title{
Цели перехода к устойчивому развитию человеческой цивилизации
}

\author{
А. Д. УРСУЛ \\ (МОСКОВСКИЙ ГОСУДАРСТВЕННЫЙ УНИВЕРСИТЕТ ИМ. М. В. ЛОМОНОСОВА) \\ T. А. УРСУЛ \\ (НАЦИОНАЛЬНЫЙ ИССЛЕДОВАТЕЛЬСКИЙ ТЕХНОЛОГИЧЕСКИЙ УНИВЕРСИТЕТ «МИСИС», \\ Г. МОСКВА)
}

До недавнего времени считалось, что для человечества, которое возникло естественным образом и развивалось стихийно, вряд ли подходит понятие цели. Но обладающее индивидуальным и общественным сознанием человечество может на определенной ступени своего развития ставить все более широкие и отдаленные по времени цели. От этого зависит его существование и дальнейшее развитие. После Конференции ООН по окружающей среде и развитию (ЮНСЕД) в 1992 г. в Рио-де-Жанейро человечество поставило цель выжить и перейти к социоприродному устойчивому развитию. Под устойчивым развитием стал пониматься наиболее приемлемый и безопасный тип социоприродной эволюции, направленной на сохранение цивилизации и биосферы, их сосуществование и коэволюцию.

На 70-й Генеральной ассамблее ООН в рамках Саммита по устойчивому развитию в сентябре 2015 г. была принята Повестка дня в области устойчивого развития до 2030 г., в которую включены 17 глобальных целей устойчивого развития. Авторы анализируют документ и делают ряд выводов. Смена целей устойчивого развития с течением времени влияет на общее понимание устойчивого развития и перспективы его реализации, но важно также обращать внимание и на концептуальные трансформации. Несовершенство современной концепции устойчивого развития оказывается одной из серьезных причин того, что человечество не может идти достаточно быстро в направлении своего выживания. Выживание зависит не только от экологических факторов. Представляется странным, что в состав целей устойчивого развития не вошла цель обеспечения мира и международной безопасности. Важно проанализировать проблему безопасности с позиций глобальных и междисциплинарных исследований и обеспечить формирование единой методологии исследования проблемы и понятия безопасности в связи с расширительной интерпретацией устойчивого развития.

Выживание цивилизации и сохранение биосферы, на чем сосредоточены основные цели устойчивого развития на весьма длительную перспективу, - это необходимое условие становления сферы разума, и они включаются в этот процесс как составная часть и одна из главных целей устойчивого развития в еще более отдаленный период времени.

Ключевые слова: устойчивое развитие; цивилизация; цели устойчивого развития; человечество; биосфера; ноосфера 


\title{
BВЕАЕНИЕ
}

\begin{abstract}
$\Lambda$ о конца второго тысячелетия считалось, что для человечества в целом, которое естественным образом возникло и развивалось стихийно, вряд ли подходит понятие цели. Эта точка зрения обосновывалась с позиций философии, так, например, в свое время О. Шпенглер отмечал, что «у человечества нет никакой цели, никакой идеи, никакого плана, также как и нет цели у вида бабочек или орхидей» (Шпенглер, 1993: 20). Конечно, приведенное О. Шпенглером сравнение человечества и биологических систем не совсем корректно. Ведь даже биоэволюция, которая не ставила «цель» появления человечества, привела к его становлению. Но обладающее индивидуальным и в какой-то мере коллективным - общественным сознанием человечество принципиально может на определенной ступени своего развития ставить все более широкие и отдаленные по времени цели, тем более если от этого зависит существование и дальнейшее развитие человечества. У человечества своя специфика эволюции, которую в целевом плане можно разделить на все прошлое развитие, которое было «бесцельным», т.е. стихийным, и пока еще остается таким, и будущее - новое, пока еще не реализованное развитие, которое может перестать быть стихийным.
\end{abstract}

\section{ЦЕАЕВЫЕ ИЗМЕРЕНИЯ АИЯ ПЕРЕХОАА К УСТОЙЧИВОМУ РАЗВИТИЮ}

Это особенно очевидно ныне, когда после Конференции ООН по окружающей среде и развитию (ЮНСЕА) в 1992 г. в Рио-де-Жанейро человечество поставило цель выжить и перейти к социоприродному устойчивому развитию. И это весьма существенный аргумент против «нецелевого» развития социальной ступени на все последующие времена. Под устойчивым развитием (УР) можно мыслить наиболее приемлемый и безопасный тип социоприродной эволюции, направленной на сохранение цивилизации и биосферы, их сосуществование и коэволюцию. При таком понимании УР существование человечества может длиться неопределенно долго и не ставит под угрозу его развитие в нерегрессивных формах.

Цель представляет собой осознанный и желаемый заранее мыслимый результат (чаще всего - полезный) сознательной деятельности человека. Целеполагание выступает как процесс формирования и определения целей, направлений и приоритетов того или иного видов деятельности, представляет базу для долгосрочного - нормативного прогнозирования и стратегического планирования деятельности.

Аля того чтобы у всего человечества в целом появились цели, оно должно стать в том или ином отношении единым, что в условиях чисто стихийного развития, даже несмотря на глобализацию и другие глобальные процессы, в принципе невозможно, хотя все формы существования и проявления человечества подчиняются ряду общих закономерностей эволюции. Переход от стихийного к осознанно-целевому развитию в глобальном масштабе делается возможным, когда стало ясным, что естественностихийное развитие чревато гибелью человечества, причем не в весьма отдаленные времена, а уже в ближайшие десятилетия. Но возможная гибель человечества - это результат стихийного прошлого и мало осознанного развития, когда индивидуальноличностное оказалось приоритетным перед общечеловеческим и цивилизационным.

Уже в XX в. перед человечеством открылись не только многочисленные возможности, новые горизонты прогресса, но и стали отчетливо видны все усиливающиеся негативные последствия стихийного развития. С одной стороны, это продвижение в области экономического, технологического, социального, Ауховно-культурного развития, а с другой - уже вполне реальные перспективы гибели человечества (либо 
большей его части) через ядерную, экологическую и другие возможные глобальные катастрофы. Ядерная катастрофа способна погубить человечество в историческое мгновение, в то время как экологическая катастрофа проявляется часто незаметно, постепенно, обрекая человечество на деградацию и сравнительно более медленное вымирание.

Именно возможность гибели человечества и деградации биосферы требует отказа от старой модели (формы) стихийного цивилизационного развития, которое неумолимо ведет к общепланетарной антропогенной катастрофе и формированию вначале в теории, а затем и на практике стратегии развития человечества, которое должно стать рационально управляемым в планетарном масштабе. Предполагается, что это станет возможным при переходе мирового сообщества к глобальному устойчивому развитию, которое позволит сохранить цивилизацию на Земле.

Еще в книге «Наше общее будущее», известной как доклад Г. Х. Брундтланд, посвященной обоснованию необходимости перехода к УР, было дано определение устойчивому развитию. Оно было обращено к будущему: «Устойчивое развитие это такое развитие, которое удовлетворяет потребности настоящего времени, но не ставит под угрозу способность будущих поколений удовлетворять свои собственные потребности» (Наше общее будущее ... , 1989: 59). Здесь, по сути, сформулирована основная цель необходимости перехода к устойчивому развитию - выживание и обеспечение существования человечества (и не только его, но, видимо, и биоты) на будущие неопределенно долгие времена.

Если мировое сообщество не примет срочных и необходимых мер, то может произойти социально-экологическая катастрофа глобального масштаба либо иная, связанная с обострением других глобальных проблем и угроз. Ведь если разразится глобально-экологическая или иная общепланетарная катастрофа, то устранять ее последствия будет просто некому. Ведь чем масштабнее катастрофа, тем труднее борьба с ее отрицательным воздействием на человечество. Поэтому способы и средства выхода из глобальных кризисов и катастроф, решения глобальных проблем в принципе должны носить опережающий характер, а не отстающий - как ныне практикуемое устранение последствий локальных чрезвычайных ситуаций и катастроф в каждой из ныне более 250 существующих признанных и непризнанных стран планеты (из них только 193 - члены ООН).

Если взять за основу социоприпродный подход к видению нового цивилизационного развития, то понятие УР может быть сформулировано в «целевом» ракурсе с помощью двух своих основных целей - антропоцентрической и биосфероцентрической. Это означает, что УР имеет в качестве основных две имманентно взаимосвязанные стратегические подцели - выживание цивилизации и сохранение биосферы, их взаимную коэволюцию.

Под антропоцентрической целью в широком смысле понимается выживание человечества и способность (и возможность) его дальнейшего непрекращающегося (устойчивого), непрерывно долгого безопасного существования и развития. Это означает, что наши потомки будут иметь не меньше возможностей по сравнению с настоящими поколениями по удовлетворению своих потребностей в обеспечении безопасности, природных ресурсах и экологических условиях Земли и космоса (принцип равенства возможностей поколений людей по удовлетворению своих витальных и других потребностей). В условиях ограниченности и даже исчерпания планетарных ресурсов и условий современные поколения (не все, конечно), по сути, живут взаймы 
за счет поколений будущих. Они фактически бездумно растрачивают природные ресурсы, создавая для предполагаемых потомков все более ухудшающиеся экологические условия существования в биосфере, что явно антигуманно, если иметь в виду стратегическую перспективу существования и эволюции человечества.

Биосфероцентрическая (в общем случае - экологическая, поскольку она должна быть распространена и на всю планету в целом, и на космос) цель связана с сохранением биосферы как естественной основы всей жизни на Земле, ее устойчивости и естественной эволюции, с тем чтобы дальнейшее развитие человечества не происходило бы в экофобной социоприродной форме. В упомянутой книге «Наше общее будущее» отмечается: «В своем самом широком смысле стратегия устойчивого развития направлена на достижении гармонии между людьми и между обществом и природой» (там же: 68). Это положение можно охарактеризовать как принцип устойчивой коэволюции природы и общества.

Очевидно, что из двух главных и взаимосвязанных целей глобального перехода к социоприродному устойчивому развитию - сохранения человечества и биосферы - наиболее приоритетной является сохранение и выживание человеческого рода. Прежде всего с этой целью и предложена была идея перехода мирового сообщества к УР. Это также означает, что в этих направлениях нужно сформулировать соответствующие цели или подцели, что делалось как на глобальном, так и на других уровнях. В этом смысле устойчивое развитие должно будет характеризоваться (как минимум) экономической эффективностью, социальной справедливостью и биосферосовместимостью при общем существенном снижении антропогенного пресса на биосферу.

Концепция УР уже не может ограничиться «целевой триадой» взаимосвязи экологии, экономики и социальной сферы, во всяком случае, в ее современном представлении. Эти три «целевые измерения» будущего перехода к УР следует существенно расширить, превратив «фазовое пространство движения к УР» в своего рода расширяющееся n-мерное пространство, где станут появляться и другие измерения, например космическое или информационное (поскольку нужно будет установить, как взаимодействует устойчивое общество с обществом информационным и другими моделями современного и будущего цивилизационного процесса).

\section{ЦЕАИ УСТОЙЧИВОГО РАЗВИТИЯ}

На 70-й Генеральной ассамблее ООН в рамках Саммита по устойчивому развитию в сентябре 2015 г. была принята Повестка дня в области устойчивого развития до 2030 года, в которую включены 17 глобальных целей устойчивого развития. По мнению руководства ООН, принятие официального документа «Преобразование нашего мира: Повестка дня в области устойчивого развития на период до 2030 года» (Преобразование нашего мира: Электронный ресурс), знаменует новый исторический этап перехода к УР всего мирового сообщества. Цели устойчивого развития (ЦУР) стали продолжением как целевых ориентиров всех предыдущих документов ООН по УР, так и целей развития тысячелетия (ЦРТ), в которых выделено в качестве приоритетных всего восемь международных целей развития и которые были приняты государствами - членами ООН в 2000 г. и должны были в основном завершены к 2015 г.

При анализе ЦУР новой Повестки дня в области УР до 2030 г. складывается впечатление, что пока не произошло какого-то существенного концептуального обновления, а тем более - теоретического инновационного прорыва. Неявно предполагается, что искомая концепция УР для всего мира уже создана и проблема заключается 
лишь в том, чтобы ее реализовать, меняя только цели развития через какой-то период времени (по-видимому, это будет уже пятнадцатилетний период). Смена ЦУР с течением времени, конечно, как-то влияет на общее понимание устойчивого развития и перспективы его реализации, но важно также обращать особое внимание и на концептуальные трансформации. Между тем несовершенство современной концепции УР все же оказывается одной из серьезных причин того, что человечество не может идти достаточно быстро в направлении своего выживания, которое зависит не только от экологических факторов, о чем также красноречиво свидетельствует обострившаяся современная геополитическая ситуация, приведшая к новой расстановке сил на мировой арене.

Представляется странным, что в состав ЦУР не вошла цель обеспечения мира и международной безопасности. Можно лишь предполагать, почему такой цели не оказалось в ЦУР, хотя ясно, УР должно быть самым безопасным типом развития человечества, обеспечивая его дальнейшее существование. Важно проанализировать проблему безопасности с позиций глобальных и междисциплинарных исследований и обеспечить формирование единой методологии исследования проблемы и понятия безопасности в связи с расширительной интерпретацией устойчивого развития.

Ясно, что без формулировки наиболее важных и приоритетных целей движения по пути УР вряд ли имеет смысл говорить о реальности становления глобального управления, хотя глобальное управление будет использовано и для иных целей. ЦУР должны будут в первую очередь затрагивать и сбалансированно охватывать как минимум три основные составляющие (экономическую, социальную и экологическую компоненты) устойчивого развития и взаимосвязи между ними, но вместе с тем будут способны охватить все сферы человеческой деятельности, во всяком случае, в их глобальном измерении.

Глобальное управление будет реализоваться различными способами в различных направлениях, например с помощью экономических, политических, экологических и других социальных способов и действий и т. д. Говоря о глобальном управлении, уместно обратить внимание на то, что в своем целостном виде этот феномен может появиться лишь в будущем, когда глобализация будет вступать в свою следующую, может быть, и не завершающую стадию, под которой мы имеем в виду управляемый переход в планетарном масштабе к устойчивому развитию. Причем процессы глобализации при переходе к УР и становлению глобального управления весьма тесно взаимосвязаны, прогресс в одном направлении будет стимулировать продвижение в другом.

Уместно также обратить внимание на то, что в уже принятой в России Концепции перехода Российской Федерации к устойчивому развитию подчеркивается, что «движение человечества к устойчивому развитию, в конечном счете, приведет к формированию предсказанной В. И. Вернадским сферы разума (ноосферы), когда мерилом национального и индивидуального богатства станут духовные ценности и знания Человека, живущего в гармонии с окружающей средой» (Концепция перехода ... : Электронный ресурс). Это положение концепции говорит о том, что Россия поставила два десятилетия тому назад еще одну, пусть пока и отдаленную, но важную в концептуальном ракурсе стратегическую и глобальную цель перехода к УР - становление ноосферы. И это весьма существенно для понимания дальнейшего движения по пути УР, который должен привести к развертыванию глобального процесса ноосферогенеза. 
Выживание цивилизации и сохранение биосферы, на чем сосредоточены основные цели устойчивого развития на весьма длительную перспективу, - это необходимое условие становления сферы разума, и они включаются в этот процесс как составная часть и одна из главных целей УР в еще более отдаленный период времени. Причем постановка этой «ноосферной» цели имеет стратегически ориентированный и приоритетный характер и глобально-космическую направленность.

Еще в первой половине прошлого века В. И. Вернадский и два французских ученых - Э. Меруа и П. Тейяр де Шарден выдвинули идею становления сферы разума - ноосферы в качестве главного направления дальнейшего развития человечества, которое должно рационализировать цивилизационный процесс и тем самым обеспечить выживание человечества. В. И. Вернадский рассматривает ноосферогенез не только как социальные или духовно-интеллектуальные трансформации, но и как естественное продолжение биосферно-геологической эволюции, в которой крупнейшей геологической силой выступает человечество (Вернадский, 1991; см. также: Урсул, 2015).

Если считать, что конечной целью перехода к устойчивому развитию является становление ноосферы, то необходимо сформировать вначале концептуально-теоретическую модель сферы разума и затем определить оптимальную траекторию ее достижения. Особенность ноосферно-футурологического подхода к исследованию будущего, в том числе и в плане реализации стратегии устойчивого развития, заключается в выдвижении на приоритетное место в грядущих трансформациях нравственно-справедливого разума и интеллектуально-духовных факторов и их опережающего воздействия и развития.

\section{ЗАКАЮЧЕНИЕ}

Ноосфера видится как гипотетическое будущее состояние и вместе с тем глобальный процесс, реализуемый через УР общества и его взаимодействие с природой, в котором приоритетное место будет занимать коллективный общечеловеческий разум, именуемый ноосферным интеллектом, направляющий эволюцию цивилизации в прогрессивно-поступательном и безопасном направлении. Устойчивое развитие в ракурсе «ноосферной цели» оказывается управляемой глобальной эволюцией, ориентированной на созидание сферы разума как нового качественного состояния и результата цивилизационного развития. Именно в ноосфере, формирующейся через переход к устойчивому развитию и становление глобального информационного общества, проявятся многие позитивные черты, которыми и сейчас обладает человек и все человечество в целом (Урсул А., Урсул Т., 2015аb).

Человечество уже начинает превращаться в единую, целостную цивилизацию ноосферы, завершая тем самым в основном локально-фрагментарные цивилизационные процессы на нашей планете появлением ноосферного этапа, сопряженного с формированием принципиально нового способа взаимодействия природы и общества на пути перехода к устойчивому развитию.

\section{СПИСОК АИТЕРАТУРЫ}

Вернадский, В. И. (1991) Научная мысль как планетное явление. М. : Наука. 271 с.

Концепция перехода Российской Федерации к устойчивому развитию [Электронный ресурс]// Кодекс. Электронный фонд правовой и нормативно-технической документации. URL: http://docs.cntd.ru/document/9017665 (дата обращения: 12.01.2016). 
Наше общее будущее. Аоклад Международной комиссии по окружающей среде и развитию (1989) : пер. с англ./ под ред. С. А. Евтеева, Р. А. Перелета. М. : Прогресс. 371 с.

Преобразование нашего мира: Повестка дня в области устойчивого развития на период до 2030 года [Электронный ресурс]// Global Compact. Network Russia. URL: http://globalcompact. ru/files_manager/Povestka_dny_v_oblasti_UR_do_2030.pdf (дата обращения: 12.01.2016).

Урсул, А.А. (2015) Феномен ноосферы: Глобальная эволюция и ноосферогенез. М. : Аенанд. $336 \mathrm{c.}$

Урсул, А. А., Урсул, Т. А. (2015а) Ноосферогенез как глобально-эволюционный процесс // Философская мысль. № 1. С. 9-92.

Урсул, А. А., Урсул, Т. А. (2015b) Перспективы ноосферогенеза. Методология ноосферных исследований. Saarbrücken : LAMBERT Academic Publishing. 328 c.

Шпенглер, О. (1993) Закат Европы. Очерки морфологии мировой истории : пер. с нем. М. : Мысль. 620 с.

Lата поступления: 20.03.2016 г.

THE GOALS OF HUMAN CIVILIZATION'S TRANSITION TO SUSTAINABLE DEVELOPMENT

A. D. URSUL

(LOMONOSOV MOSCOW STATE UNIVERSITY)

T. A. URSUL

(НАЦИОНАЛЬНЫЙ ИССЛЕДОВАТЕЛЬСКИЙ ТЕХНОЛОГИЧЕСКИЙ УНИВЕРСИТЕТ «МИСИС», Г. МОСКВА)

Until recently, it has been commonly held that since mankind had been naturally evolving over millennia, the notion of goal cannot be applied to its development. However, possessing both individual and collective consciousness, at a certain stage humanity is able to start positing ever wider and more distant goals. It is on this goal-setting that the survival and progress of mankind ultimately depend. At the UN Conference on Environment and Development (UNCED) held in Rio de Janeiro in 1992, mankind confirmed its commitment to survival and transition to social and natural sustainable development. Sustainable development is now understood as the most acceptable and most secure type of social and natural evolution, aimed at preserving the civilization and biosphere, as well as at their coexistence and coevolution.

In September 2015, the UN Sustainable Development Summit, working as part of the $70^{\text {th }}$ session of the UN General Assembly, adopted the 2030 Agenda for Sustainable Development. It comprises 17 global goals for sustainable development.

Our analysis of this document led us to a conclusion that the change of sustainable development priorities over time will have an impact on our general understanding of sustainable development and its prospects. Another important focus is to be made on its conceptual transformations. The contemporary concept of sustainable development is imperfect, which prevents mankind from moving to survival at a sufficiently fast pace. Survival itself is more than just an environmental factor. It is rather strange that the goal of providing global peace and security was not named among the goals of sustainable development. It is thus important to analyze the issue of security from a global and interdisciplinary standpoint and to create a single methodology and common understanding of security, given the wider interpretation of sustainable development.

The survival of civilization and the preservation of the biosphere - the main long-term priorities of sustainable development - are the required preconditions for the noosphere, and the genesis of the noosphere is to become one of sustainable development's priorities for a still more distant future.

Keywords: sustainable development; civilizations; sustainable development goals; mankind; biosphere; noosphere

Vernadskii, V. I. (1991) Nauchnaia mysl' kak planetnoe iavlenie [Scientific thought as a planetscale phenomenon]. Moscow, Nauka Publ. 271 p. (In Russ.). 
Kontseptsiia perekhoda Rossiiskoi Federatsii k ustoichivomu razvitiiu [Concept for the Transition of the Russian Federation to Sustainable Development]. Kodeks. Elektronnyi fond pravovoi i normativno-tekbnicheskoi dokumentatsii [on-line] Available at: http://docs.cntd.ru/document/9017665 (access date: 12.01.2016). (In Russ.).

Nashe obshchee budushchee. Doklad Mezbdunarodnoi komissii po okruzhaiushchei srede i razvitiiu (1989) [Our common future: Report of the World Commission on Environment and Development]. Moscow, Progress Publ. 371 p. (In Russ.).

Preobrazovanie nashego mira: Povestka dnia v oblasti ustoichivogo razvitiia na period do 2030 goda [Transforming our world: the 2030 Agenda for sustainable development]. Global Compact. Network Russia [Online] Available at: http://globalcompact.ru/files_manager/Povestka_dny_v_oblasti_UR_do_2030.pdf (access date: 12.01.2016). (In Russ.).

Ursul, A. D. (2015) Fenomen noosfery: Global' naia evoliutsiia i noosferogenez [The phenomenon of noosphere: Global evolution and the genesis of noosphere]. Moscow, Lenand Publ. 336 p. (In Russ.).

Ursul, A. D. and Ursul, T. A. (2015a) Noosferogenez kak global'no-evoliutsionnyi protsess [The genesis of noosphere as a process of global evolution]. Filosofskaia mysl', no. 1, pp. 9-92. (In Russ.).

Ursul, A. D. and Ursul, T. A. (2015b) Perspektivy noosferogeneza. Metodologiia noosfernykb issledovanii [Noosphere genesis and its prospects: A methodology for noosphere studies]. Saarbrücken, LAMBERT Academic Publishing. 328 p. (In Russ.).

Spengler, O. (1993) Zakat Evropy. Ocherki morfologii mirovoi istorii [The decline of the West: Morphology of world history]. Moscow, Mysl' Publ. 620 p. (In Russ.).

Submission date: 20.03.2016.

Урсул Аркадий Амитриевич - доктор философских наук, профессор, директор Центра глобальных исследований факультета глобальных процессов Московского государственного университета им. М. В. Аомоносова; академик Академии наук Молдавии, заслуженный деятель науки РФ. Адрес: 119991, Россия, г. Москва, Аенинские горы, д. 1, стр. 51. Тел.: +7 (495) 939-43-23. Эл. адрес: ursul-ad@mail.ru

Урсул Татьяна Альбертовна - доктор философских наук, профессор, заведующая кафедрой социальных наук и технологий Национального исследовательского технологического университета «МИСиС», почетный работник высшего профессионального образования РФ. Адрес: 119049, Россия, г. Москва, Аенинский пр-т, А. 6. Тел.: +7 (499) 237-65-80. Эл. aдpec: ursult@ mail.ru

Ursul Arkady Dmitrievich, Doctor of Philosophy, Professor, Director, Center for global studies, Faculty of Global Studies, Lomonosov Moscow State University; Fellow, Academy of Sciences of Moldova, Honored Scientist of the Russian Federation. Postal address: 1, Bldg.51, Leninskie Gory, Moscow, Russian Federation 119991. Tel.: +7 (495) 939-43-23. E-mail: ursul-ad@mail.ru

Ursul Tatiana Al'bertovna, Doctor of Philosophy, Professor and Chair, Department of Social Sciences and Technologies, National University of Science and Technology MISiS; Honored Worker of Higher Education of Russian Federation. Postal address: 6 Leninski Prospekt, Moscow, Russian Federation 119049. Tel.: +7 (499) 237-65-80. E-mail: ursult@mail.ru 